\title{
Skilled Birth Attendant (SBA) and Home Delivery in India: A Geographical Study
}

\author{
Mayank Kumar Singh ${ }^{1 *}$, Krishan Chand Ramotra ${ }^{2}$ \\ ${ }^{1,2}$ Department of Geography, Shivaji University, Kolhapur, India
}

\begin{abstract}
:
Objective: Objectives of this paper is to identify the regional gap in receiving services from SBA for delivery being conducted at home in India as well as to explore the determinant of safe delivery at home.

Data and methods: We have used cross-sectional data from all three rounds of National Family Health Survey (NFHS) conducted during 1992-93, 1998-99 and 2005-06. We have used bivariate, chi square test and logistic regression for the present study.

Results: Thirty Seven percent of total delivery was conducted in health facility whereas $13 \%$ of home deliveries were assisted by SBA in India. India is still behind in receiving SBA services compared to MDG goal among currently married women which is 100 percent with respect to the goal defined by the United Nations. Results show that safe home delivery is significantly associated with education of mother, religion, wealth quintile, birth order and ANC visit. Further the variables like higher educated mother, Muslim women, women from higher wealth quintile in receiving ANC services during pregnancy were the beneficiary in receiving services from SBA as well during home delivery. Thus, in all three rounds of NFHS the progress in this regard is still lagging behind after numerous efforts being made by government. Women from Uttar Pradesh, Bihar and Arunachal Pradesh were receiving less SBA service at home delivery.

Conclusion: Main predictor of safe home delivery is education of mother, religion, wealth quintile, birth order and ANC visits. It is very unfortunate that a delivery is taking place at home if it is so then at least it should be conducted by skilled birth attendant (SBA). Government have got to convince the populace for institutional delivery so that the untimely deaths of women can be averted with proper treatment and safe delivery. Women should schedule in advance for delivery during pregnancy so that safe delivery can take place and also the number of maternal deaths can be reduced. Besides this government should focus on poor uneducated and younger rural women as well as it should ensure at least four ANC visits for every pregnant woman as well. So that maternal mortality can be combated on time.
\end{abstract}

\section{Introduction}

At global level, each year 350,000 maternal deaths happen and 2 million newborns die within first 24 hours of life. Majority of these deaths occur in low-income countries and most of the death can be averted through modern health care [3]. Delivery conducted by SBAs is the fifth Millennium Development Goal (MDG) and an indicator of progress towards reducing maternal mortality worldwide [21].

Many studies have shown that delivery conducted by SBA reduces probability of maternal and child death during delivery because almost all obstetric complications happen around the time of delivery $[2,4$, and 5]. Maternal Mortality Ratio (MMR) has a direct impact on infant mortality and those children whose mothers die during first 6 weeks of delivery are more likely to die in the first two years of life than those babies whose mothers survive [12, 14, and 13]. World Health Organization (WHO) defines skilled birth attendant (SBA) as "an accredited health professional such as a midwife, doctor or nurse who has been educated and trained to proficiency in the skills needed to manage normal pregnancies, childbirth and immediate postnatal period, and in the identification, management and referral of complications in women and newborns" [1].

Seventy percent of India's population still live in rural area and most of these populations are yet far away to access basic health facility. NFHS-3 report shows that only $38 \%$ women are going for institutional delivery in India and remaining deliveries being conducted at home [9]. These deliveries still depend on traditional health provider or skill birth attendant. In this study, we have identified the gap of skill birth attendant for home delivery through trend and regional variation of home delivery conducted by SBA. Through this study we have identified the determinant of home delivery conducted by SBA and determinant of safe delivery. Because almost all complications which arises can be attended by SBA and if the condition of women get worse then it is referred to higher level. 


\section{Data and method}

We have used cross-sectional data from all three rounds of National Family Health Survey (NFHS) conducted during 1992-93, 1998-99 and 2005-06 [6, 7, and 8]. NFHS is a nationally representative, large scale, multi-round survey in a representative sample of households throughout India.

To make the estimates representative and to account for the multi-stage sampling design has been adopted, we have used appropriate weights in the analysis. The details of the sampling weights are given in NFHS reports of various rounds [7. 8]. The present analysis is restricted to 28,316 children below five years of age.

\section{Exposure variable and Outcome variable}

This study utilized several exposure variables that are age of respondent, place of residence, educational status, media exposure, marital status, employment status, religion, wealth quintile, birth order, women autonomy, ANC visits and caste of the respondents. Skill birth attendant (SBA) at home delivery is the outcome variable of this study.

\section{Analytical Approach}

Bivariate, Chi-square test and logistic regression analysis have been used to full fill the objective of the present study.STATA-12.0, ArcMap-10 and Origin-8 software is used for data analysis, preparing map and figure, respectively.

\section{Results}

Only, $38 \%$ of deliveries were conducted in health facility and rest of the delivery at home. Thus, result show that only $13 \%$ of home delivery were conducted by Skilled Birth Attendant (SBA) in India.

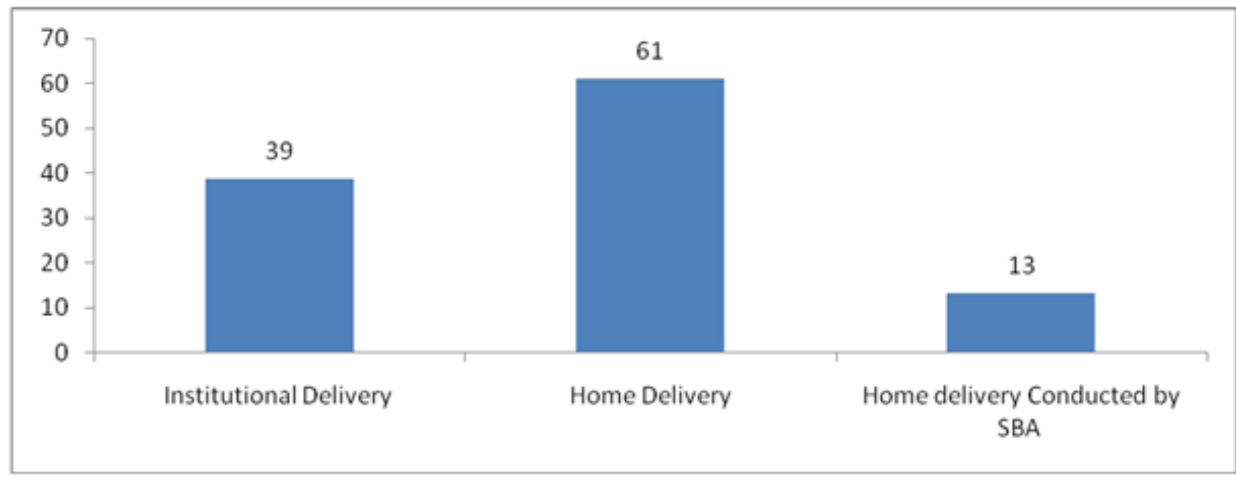

Figure 1: Safe Delivery Status in India, 2005-06

Table 1 is showing the trend in Home delivery conducted by Skill Birth attendant. It is apparent from the table that the southern part of the country is having the highest percentage of the skilled birth attendant 20.5 percent and it is showing an increase in the successive rounds of the survey. We can see that it is the lowest in the region of east India only 5.5 percent and in round three it is 11.7 percent which is below the national average which is 10.5 percent and 13.4 percent respectively.

Table 1: Trend in Home delivery conducted by Skill Birth attendant(SBA)

\begin{tabular}{|l|l|l|l|l|l|l|l|}
\hline Years & North & East & Northeast & Central & West & South & India \\
\hline $1992-93$ (NFHS-1) & 15.7 & 5.5 & 8.9 & 7.5 & 15.6 & 20.5 & 10.5 \\
\hline $1998-99$ (NFHS-2) & 21.9 & 10.2 & 7.6 & 9.7 & 14.1 & 24.6 \\
\hline 2005-06(NFHS-3) & 18.8 & 11.7 & 10.7 & 10.4 & 17.1 & 25.1 & 13.4 \\
\hline
\end{tabular}


Figure 2 Shows that Uttar Pradesh, Uttarakhand and Arunachal Pradesh are worse performing states in India.
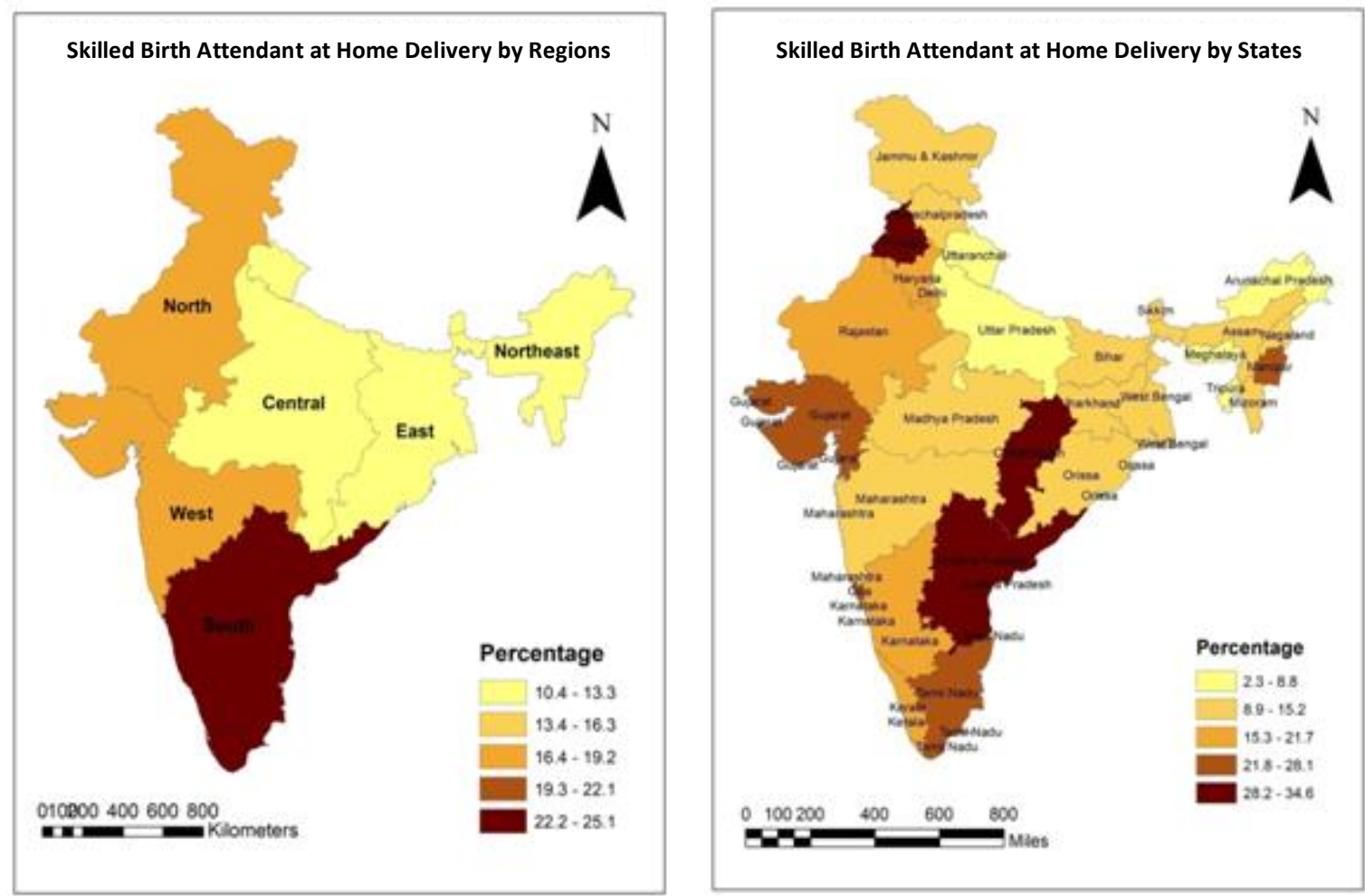

Figure 1

(A)

(B)

Figure 2: Skilled Birth Attendant (SBA) at home delivery by region and states (India)

Table 2 represents the percentage of live birth delivered by any health professionals at home in different regions of India according to selected background characteristics. Delivery attended by any health professional was found to be highest in the southern region 24.3 percent in the age group 15-19 years whereas it was lowest in the North East region which is 9.1 percent in 15-19 years which is below the national average which shows that it is demographically less developed and needs further more attention towards more people going for delivery attended by health professional at home which will ward off the maternal deaths occurring due to negligence. Those people who belong to other religion are having delivery conducted by health professional at home 43.3 percent followed by Hindu religion 17.8 percent in the northern region. It is lowest in the Northeast region 7.6 percent in the Muslim religion category followed by the other religion category which is 7.6 percent. People belonging to the poorest wealth quintile in the northeast region are having the lowest percentage for delivery of live birth by health professional which is only 4.1 percent

Table 2: Percentage of home delivery assisted by any health professional at home by Region, according to background characteristics, India, 2005-06

\begin{tabular}{|c|c|c|c|c|c|c|c|c|c|c|c|c|c|c|}
\hline $\begin{array}{l}\text { Background } \\
\text { Characteristics }\end{array}$ & $\begin{array}{l}\text { Nort } \\
\mathrm{h} \\
(\%)\end{array}$ & $\mathrm{N}$ & $\begin{array}{l}\text { North } \\
\text { east( } \\
\%)\end{array}$ & $\mathrm{N}$ & $\begin{array}{l}\text { South } \\
(\%)\end{array}$ & $\mathrm{N}$ & $\begin{array}{l}\text { West } \\
(\%)\end{array}$ & $\mathrm{N}$ & $\begin{array}{l}\text { East } \\
(\%)\end{array}$ & $\mathrm{N}$ & $\begin{array}{l}\mathrm{Ce} \\
\text { ntr } \\
\text { al( } \\
\%\end{array}$ & $\mathrm{~N}$ & $\begin{array}{l}\text { India } \\
(\%)\end{array}$ & $\mathrm{N}$ \\
\hline \multicolumn{15}{|c|}{ Age group of mother } \\
\hline $15-19$ & 19.7 & 563 & 9.9 & 1,023 & 29.2 & 386 & 16.1 & 286 & 12.1 & 994 & $\begin{array}{l}13 \\
.8 \\
11\end{array}$ & 1,280 & 15.4 & $\begin{array}{l}4,65 \\
3 \\
10,4\end{array}$ \\
\hline $20-24$ & 21.9 & 1,797 & 13.8 & 1,968 & 25.6 & 622 & 18.3 & 748 & 14.4 & 1,788 & $\begin{array}{l}.8 \\
9 .\end{array}$ & 3,324 & 15.6 & $\begin{array}{l}47 \\
9,77\end{array}$ \\
\hline $25-34$ & 16.1 & 1,654 & 10.0 & 2,343 & 21.3 & 368 & 16.0 & 515 & 9.7 & 1,766 & $\begin{array}{l}1 \\
6 .\end{array}$ & 3,350 & 11.3 & $\begin{array}{l}4 \\
1,57\end{array}$ \\
\hline \multirow[t]{2}{*}{$35-49$} & 12.2 & 261 & 6.9 & 445 & 23.0 & 45 & 13.3 & 33 & 9.6 & 304 & $\begin{array}{l}2 \\
\operatorname{chi} 2(3\end{array}$ & )$^{575}=$ & $\begin{array}{l}8.94 \\
\text { chi2(3) }\end{array}$ & $4=$ \\
\hline & \multicolumn{2}{|c|}{$\begin{array}{l}\operatorname{chi} 2(3)=15.7 \\
\operatorname{Pr}=0.001\end{array}$} & \multicolumn{2}{|c|}{$\begin{array}{l}\operatorname{chi} 2(3)=15.6 \\
\operatorname{Pr}=0.01\end{array}$} & \multicolumn{2}{|c|}{$\begin{array}{l}\operatorname{chi} 2(3)=6.89 \\
\operatorname{Pr}=0.08\end{array}$} & \multicolumn{2}{|c|}{$\begin{array}{l}\operatorname{chi} 2(3)=0.63 \\
\operatorname{Pr}=0.89\end{array}$} & \multicolumn{2}{|c|}{$\begin{array}{l}\operatorname{chi} 2(3)=18.7 \\
\operatorname{Pr}=0.000\end{array}$} & \multicolumn{2}{|c|}{$\begin{array}{l}32.2 \text { Pr }= \\
0.000\end{array}$} & $\begin{array}{l}67.19 \\
0.000\end{array}$ & $\operatorname{Pr}=$ \\
\hline
\end{tabular}




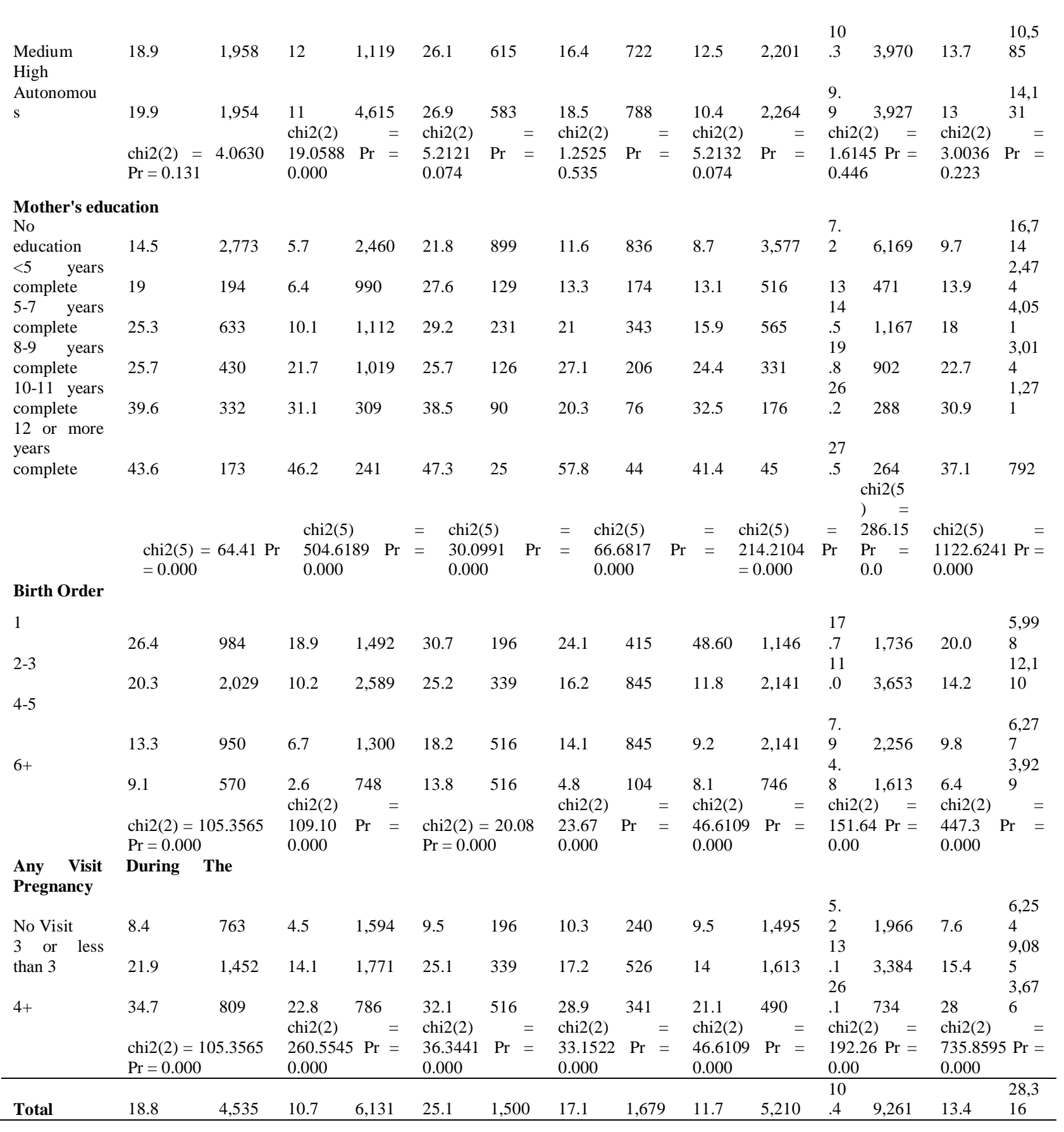

respectively and it is the highest for the richest wealth quintile 34.1 percent whereas the southern region is outperforming rest of the region in terms of delivery attended by skilled health professional 21.3 percent in the poorest wealth quintile, however the richest quintile shows 43.3 percent people going for delivery skilled health professional. Exposure to media was also playing an important role in determining the place of delivery and delivery by skilled health professional.SC/ST population in the central region is showing the least number of deliveries attended by the skilled health professional 8.3 percent which is below the national average of 11 percent. Number of household whose place of residence is urban are having more number of delivery attended by skilled health professional then the rural counter parts, whereas in southern India the difference is not very much significant urban is 26.8 percent and rural is 24.6 percent. Eastern region is showing the lowest percentage of delivery attended by skilled health personnel which is only 15.4 percent also it is below the national average of 19.6 percent. Four or more number of visits during pregnancy is lowest in the northeast region 22.8 percent followed by 3 or less than 3 i.e., 14.1 percent. 


\section{Determinants of delivery conducted by any health professional at Home:}

The table 3 shows the logistic regression showing the influence of health professional conducting delivery at home in India. Main predictor of safe home delivery is mother's education, religion, wealth quintile, birth order and ANC visit. Interesting point is that age of mother was inversely related to safe delivery at home after including birth order. Those women belonging to age group 35-49 are 31 percent more likely to have health professional at home for delivery than below 19 years. Women belonging to Muslim religion are 33 percent less likely to have health professional at home. Likelihood of receiving safe delivery at home increases with increase in wealth index and it is least for the women belonging to poorest wealth quintile in India. These results are consistent with the finding of bi-variate analysis. Those women who belong to $\mathrm{OBC}(\mathrm{OR}=1.28, \mathrm{CI}=$ $1.15-1.43)$ or general category $(\mathrm{OR}=1.12, \mathrm{CI}=0.99-1.27)$ are more likely to have health professional at home for delivery than SC/ST women. As the number of years of education is positively associated with delivery conducted by health professional at home and women who received 12 or more years of education, are $80 \%$ more likely to receive safe delivery at home. For those women whose place of residence is rural they are 11 percent less likely to have a health professional at the time of delivery than their counterpart in India. Increasing number of ANC visits is increasing positively for safe delivery at home and those women who had 4+ visits are 2.8 times more likely to have health professional at home for delivery. Result also verify that women from southern region $(\mathrm{OR}=1.33, \mathrm{CI}=1.10$ - 1.62) are more likely to receive services of SBA as compared to northern region. Women from northeast and central region are less likely to receive safe delivery services compared to northern region.

Table 3: Logistic regression showing variables influencing the health professional at home delivery in India, 2005-2006

\begin{tabular}{|c|c|c|}
\hline Predictors & Odds Ratio & [95\% Conf. Interval] \\
\hline \multicolumn{3}{|l|}{ Age of mother at birth } \\
\hline $15-19 \circledR$ & 1 & \\
\hline $20-24$ & 1.04 & $0.90-1.20$ \\
\hline $25-34$ & $1.17^{* *}$ & $1.00-1.38$ \\
\hline $35-49$ & $1.31 * *$ & $1.02-1.70$ \\
\hline \multicolumn{3}{|l|}{ Religion } \\
\hline Hindu $®$ & 1 & \\
\hline Muslim & $0.67 * * *$ & $0.58-0.78$ \\
\hline Other & 1.07 & $0.91-1.26$ \\
\hline \multicolumn{3}{|l|}{ Wealth index } \\
\hline Poorest ${ }^{\circledR}$ & 1 & \\
\hline Poorer & 1.04 & $0.91-1.20$ \\
\hline Middle & $1.27 * * *$ & $1.09-1.47$ \\
\hline Richer & $1.70^{* * *}$ & $1.45-2.01$ \\
\hline Richest & $1.91 * * *$ & $1.55-2.36$ \\
\hline \multicolumn{3}{|l|}{ Media Exposure } \\
\hline No® & 1 & \\
\hline Yes & $1.22 * * *$ & $1.09-1.37$ \\
\hline \multicolumn{3}{|l|}{ Caste groups } \\
\hline SC/ST® & 1 & \\
\hline $\mathrm{OBC}$ & $1.28 * * *$ & $1.15-1.43$ \\
\hline Other & $1.12 *$ & $0.99-1.27$ \\
\hline \multicolumn{3}{|l|}{ Work status } \\
\hline No® & 1 & \\
\hline Yes & $1.10^{* *}$ & $1.00-1.20$ \\
\hline \multicolumn{3}{|l|}{ Type of place of residence } \\
\hline Urban $®$ & 1 & \\
\hline Rural & $0.89 * *$ & $0.80-0.99$ \\
\hline \multicolumn{3}{|l|}{ Husband's education } \\
\hline No education ${ }^{\circledR}$ & 1 & \\
\hline$<5$ years complete & 1.04 & $0.87-1.24$ \\
\hline 5-7 years complete & 1.09 & $0.95-1.25$ \\
\hline $8-9$ years complete & $1.18^{* *}$ & $1.02-1.36$ \\
\hline $10-11$ years complete & 1.13 & $0.97-1.33$ \\
\hline 12 or more years complete & $1.38 * * *$ & $1.17-1.64$ \\
\hline \multicolumn{3}{|l|}{ Respondent's education } \\
\hline No education ${ }^{\circledR}$ & 1 & \\
\hline$<5$ years complete & 1.14 & $0.96-1.34$ \\
\hline 5-7 years complete & $1.23 * * *$ & $1.08-1.4$ \\
\hline $8-9$ years complete & $1.33^{* * *} *$ & $1.15-1.54$ \\
\hline $10-11$ years complete & $1.57 * * *$ & $1.31-1.9$ \\
\hline 12 or more years complete & $1.82 * * *$ & $1.46-2.28$ \\
\hline \multicolumn{3}{|l|}{ Birth Order } \\
\hline $1 \AA$ & 1 & \\
\hline $2-3$ & $0.72 * * *$ & $0.64-0.81$ \\
\hline $4-5$ & $0.56^{* * *}$ & $0.47-0.66$ \\
\hline
\end{tabular}




\begin{tabular}{|c|c|c|}
\hline $6+$ & $0.44^{* * *} *$ & $0.35-0.55$ \\
\hline \multicolumn{3}{|l|}{ Women autonomy } \\
\hline Low Autonomous® & 1 & \\
\hline Medium Autonomous & 1.08 & $0.93-1.25$ \\
\hline High Autonomous & 1.12 & $0.96-1.30$ \\
\hline \multicolumn{3}{|c|}{ ANC Visit During The Pregnancy } \\
\hline No Visit@ & 1 & \\
\hline 3 or less than 3 & $2.07 * * *$ & $1.83-2.33$ \\
\hline $4+$ & $2.82^{* * *} *$ & $2.46-3.24$ \\
\hline \multicolumn{3}{|l|}{ Region } \\
\hline North® & 1 & \\
\hline East & 1.05 & $0.90-1.22$ \\
\hline Northeast & $0.86^{*}$ & $0.73-1.01$ \\
\hline Central & $0.85^{* *}$ & $0.75-0.97$ \\
\hline West & 0.97 & $0.80-1.17$ \\
\hline South & $1.33 * * *$ & $1.10-1.62$ \\
\hline
\end{tabular}

. $\mathrm{P}$ values- $* * *$ Significant at 1 percent; $* *$ Significant at 5 percent; * Significant at 10 percent.

®- Reference category.

\section{Discussion}

The main causes of maternal deaths have been recognized as haemorrhage, sepsis, obstructed labour, toxaemia, and unsafe abortion. The majority of these can be averted if complications during pregnancy and childbirth can be recognized and managed early. This can be achieved only if deliveries at a health facility or in community are conducted by a skilled birth attendant (SBA). Several studies from many countries show that presence of skilled birth attendant (SBA) at birth can effectively decrease maternal mortality [10] .Government of India has a dedicated programme under NRHM/RCH to ensure widespread coverage of all births with skilled attendance both in the institution and at community level and to provide access to emergency obstetric care services and neonatal care services for women and the new born. For full filling this purpose, skilled birth attendant training for ANMs/LHVs/SNs has been carried out in all the State of India to equip ANMs and Staff Nurses for controlling normal deliveries, identify complications, basic management and then refer at the earliest to higher health facilities thereby empowering them to save the life of both the mother and new born [9].

This study has identified several determinants that have significant influence on the skill birth attendant conducted deliveries at home such as women's education, age of mother, birth order, caste, and religion, economic status of household and place of residence. Main dominant predicator of SBA attendant home delivery in India is four or more ANC visits, education of mother and wealth index.

Finding shows that very less percentage of women is receiving health facility in India. Many studies also showed that Traditional Birth Attendant (TBA) are seen as feasible and accessible at any time in the village compared to Community health facility [15, 16, 22]. In India, low utilization of SBA services occur due to poor quality services, unavailability and inaccessibility of services, minimum staff support, shortage of medicine and equipment as well as deficient referral systems [23].

Furthermore education is positively associated in utilization of safe delivery and those mothers who are more educated are more likely to receive safe delivery compared to those mothers who are illiterate. Educated women are more aware and know the need for SBA during delivery. In addition, educated women also have superior decision making power on seeking health services and have the capability to move outside home $[17,18$, and 20].

The safe delivery was found to be significantly lower among Muslim women than Hindu Lower utilization of safe delivery services among Muslim women could be linked to their lower socio-economic status. Women from Scheduled Castes, /Scheduled Tribes and Other Backward Caste were less likely to utilize safe delivery facility compared to Upper caste women. Lower castes like SC/ST are considered as a socially disadvantaged group and are outcasted by the society this. The disparity in the use of safe delivery facility across economic group is a more concern issue among policy makers.

Wealth quintile status of household was found to be significant factor affecting the utilization of safe delivery in India [11]. Women from the wealthier groups were more likely to utilize safe delivery services at home than poor women in addition people spend more on health care than the poor counterpart.

Finding shows that ANC visits is one of the main predictor of receiving safe delivery [24] at home. Women, who visit for any antenatal services, can interact with the health professional at the health facility and know possible risks of pregnancy as well as be aware of the importance of SBA during delivery [19, 20].

Result from this study clearly shows the importance of place of residence in determining safe delivery. Further it shows that children belonging to other region are less likely to receive safe delivery compared to southern region's women. Most of the southern states are more economically and demographically developed than northern and eastern states of India. 
Northeast, East and Central region is poor performing regions. Uttar Pradesh in central region, Rajasthan in Northern region and Arunachal Pradesh in north-eastern region is poor performing state. Government should focus on socio-economically poor family of these states for better utilization of institutional facility during delivery as well as to ensure for a woman to receive at least four ANC visit during pregnancy.

\section{Conclusion}

Main predictor of safe home delivery is mother's education, religion, wealth quintile, birth order and ANC visits. It is very unfortunate if delivery takes place at home, $100 \%$ should be conducted by SBA as it is one of the goal set by the United Nation for MDG. Government should also encourage for institutional delivery and where it is not possible at least the home delivery should be carried out by SBA. In addition, government should focus on poor, uneducated and younger rural women as well as ensure at least four ANC visit for every pregnant woman.

\section{References}

[1]. WHO (2005). The WHO and the Millennium Development Goals. Fact sheet no. 290. World Health Organization, Geneva. 2005.

[2]. Montgomery AL, Fadel S, Kumar R, Bondy S, Moineddin R, et al. (2014) The Effect of Health-Facility Admission and Skilled Birth Attendant Coverage on Maternal Survival in India: A Case-Control Analysis. PLoS ONE 9(6): e95696. doi:10.1371/journal.pone.0095696

[3]. UNFPA (2011). The State of World's Midwifery- Delivering Health, Saving Lives. 2011:5.Available: http://www.who.int/pmnch/media/membernews/2011/2011_sowmr_en.pdf

[4]. Graham WJ, Bell JS, Bullough CHW (2001) Can skilled attendance at delivery reduce maternal mortality in developing countries? Antwerp: ITGPress. 97-130.4

[5]. Loudon I (1992) Death in childbirth, illustrated edition. Oxford: Clarendon Press.

[6]. International Institute for Population Sciences (IIPS) (1995) National Family Health Survey (MCH and Family Planning), India 1992-93. Bombay: IIPS.

[7]. International Institute for Population Sciences (IIPS) \& ORC MACRO (2000) National Family Health Survey (NFHS-2), 1998-99: India. Mumbai: IIPS

[8]. International Institute for Population Sciences (IIPS) \& Macro International (2007) National Family Health Survey (NFHS-3), 2005-06: India, Volume I. Mumbai: IIPS.

[9]. National Rural Health Mission (2010). Guidelines for Antenatal Care and Skilled Attendance at Birth by ANMs/LHVs/SNs. Ministry of H\&FW, Government of India.pp.1-105

[10]. NRHM(2010).Skill birth attendance(SBA):A handbook for auxilary nurse midwives lady health visitor \& staff nurse 2010. Ministry of H\&FW, Government of India.pp.1-69

[11]. Pathak PK, Singh A, Subramanian SV (2010) Economic Inequalities in Maternal Health Care: Prenatal Care and Skilled Birth Attendance in India, 1992-2006. PLoS ONE 5(10): e13593. doi:10.1371/journal.pone.0013593

[12]. UNICEF. Maternal Health in India. Available:http://www.unicef.org/india/health.html

[13]. WHO Regional Office for Africa. The Health of the People: The African Regional Health Report. (WHO: Geneva: 2006) p.19

[14]. Ronsmans, Carine, Mahbub Chowdhury, Sushil Dasgupta, Anisuddin Ahmed and Marge Koblinsky. "Effect of Parent's Death on Child Survival in Rural Bangladesh: A Cohort Study." The Lancet. Volume 375, Issue 9730. June 2010. pp.2024-2031

[15]. Essendi H, Mills S, Fotso JC: Barriers to formal emergency obstetric care services' utilization. J Urban Health 2011, 88(Suppl 2):S356-S369.

[16]. Amooti-Kaguna B, Nuwaha F: Factors influencing choice of delivery sites in Rakai district of Uganda. Soc Sci Med 2000, 50:203213 .

[17]. Mekonnen, Y. and Mekonnen, A., "Factors influencing the use of maternal healthcare services in Ethiopia",Journal of health, population and nutrition, 21(4), p:374-382, 2003.

[18]. Tann, C.J., Kizza, M., Morison, L., Mabey, D., Muwanga, M., Grosskurth, H. and Elliott, A.M., "Use of antenatal services and delivery care in Entebbe, Uganda: a community survey", BMC pregnancy and childbirth, 7(23), 2007.

[19]. Gabrysch, S. and Campbell, O.M., "Still too far to walk: literature review of the determinants of delivery service use", BMC pregnancy and childbirth, 9(34), 2009.

[20]. Md. Atiqul Hoque Chowdhury, Md. Mehedi Hasan, Sayem Ahmed, Charls Darwin, Mohammad Sazzad Hasan, and Md. Rabiul Haque, "Socio-demographic Factors Associated with Home Delivery Assisted by Untrained Traditional Birth Attendant in Rural Bangladesh." American Journal of Public Health Research 1, no. 8 (2013): 226-230. doi: 10.12691/ajphr-1-8-6.

[21]. Carlough M, McCall M. Skilled birth attendance (2005): What does it mean and how can it be measured? A clinical skills assessment of maternal and child health workers in Nepal. Int J Gynaecol Obstet 2005;89:200-208.

[22]. Kyaw Oo, Le Le Win, Saw Saw, Myo Myo Mon, Yin Thet Nu Oo, Thae Maung Maung, Su Latt Tun Myint, Theingi Myint (2012). Challenges faced by skilled birth attendants in providing antenatal and intrapartum care in selected rural areas of Myanmar. WHO South-East Asia Journal of Public Health 2012; 1(4):467-476

[23]. Baral YR, Lyons K, Skinner J, van Teijlingen ER: Determinants of skilled birth attendants for delivery in Nepal. Kathmandu Univ Med J 2010, 8:325-332.

[24]. Choulagai B, Onta S, Subedi N, Mehata S, Bhandari GP et al.(2013). Barriers to sing skilled birth attendants' services in mid- and far-western Nepal: a cross-sectional study. BMC International Health and Human Rights 2013 13:49. 